\title{
Leptin and the obesity hypoventilation syndrome: a leap of faith?
}

\section{Fitzpatrick}

A possible role for leptin or its analogues in the treatment of the obesity hypoventilation syndrome

$\mathrm{T}$ he discovery of the anti-obesity hormone leptin (the name is derived from the Greek "leptos" meaning "thin"), the product of the ob gene, ${ }^{1}$ has fuelled a recent surge of interest in the mechanisms regulating mammalian fat stores. Leptin, a $16 \mathrm{kD}$ protein of 167 amino acids with a similar crystal structure to cytokines, ${ }^{2}$ is produced primarily by white adipose tissue. ${ }^{3}$ The hormone elicits appetite suppression and weight loss. ${ }^{45}$ Leptin circulates in the plasma in the free and protein bound forms. Circulating plasma leptin levels reflect the amount of energy storage in adipose tissue and increase exponentially with increasing fat mass. ${ }^{6}$ Plasma leptin levels also respond to short term energy imbalance, increasing during periods of overfeeding and decreasing with fasting. ${ }^{78}$ The hormone activates specific receptors ${ }^{9}$ located at several sites throughout the brain, but plays a key role at the hypothalamus, in particular, where it alters the expression of several hypothalamic neuropeptides. ${ }^{10}{ }^{11}$ One of these, neuropeptide Y (NPY), is a potent stimulator of food intake and activator of the hypothalamic-pituitary-gonadal axis. Leptin inhibits synthesis of hypothalamic NPY and downregulation of NPY is associated with appetite suppression, increased sympathetic nervous system outflow, and increased energy expenditure. ${ }^{12}$ Increasing leptin levels activate the thyroid hormone, gonadal, and growth hormone axes and suppress the pituitary-adrenal axis. ${ }^{13}$ It must be emphasised that human obesity is a complex disorder, probably resulting from both multigenetic and environmental predispositions, and that leptin deficiency is a very rare cause of human obesity. ${ }^{14}$ Indeed, circulating leptin levels are typically higher than normal in human obesity, indicating that it is a leptin resistant state. ${ }^{15}$ Even within the hypothalamus the NPY axis is clearly not a final common pathway for appetite control as the appetite stimulating orexins can induce feeding despite blockade of the NPY axis. ${ }^{16}$

\section{REGULATION OF LEPTIN PRODUCTION}

Leptin production is regulated by several factors. ${ }^{17}{ }^{18}$ Insulin and glucocorticoids act directly on adipocytes to increase leptin production, and chronic hyperinsulinaemia and increased cortisol turnover may underlie the increase in leptin expression observed in obesity. Similarly, the observed increase in serum leptin levels 4-7 hours after meals is probably related to increased circulating insulin in concert with the permissive effects of cortisol. Fasting results in decreased serum leptin levels-probably through falling insulin levels and the ability of catecholamines to decrease leptin expression (isoproterenol and $\beta_{3}$ adrenergic receptor agonists reduce leptin production by adipocytes). Women have been noted to have higher serum leptin levels than men, and this could relate to a difference in body fat composition between the sexes or the permissive effects of oestrogen and progesterone on leptin production. Under conditions of constant enteral feeding, circulating leptin levels are higher at night than during the day; in addition to a small circadian influence, sleep is associated with an increase in plasma leptin levels in normal subjects. ${ }^{19}$

\section{EFFECTS OF LEPTIN ON RESPIRATION}

Apart from its anti-obesity effects, leptin exerts important physiological effects on the control of respiration. $.^{20} \mathrm{Ob} / \mathrm{ob}$ mice, which lack the gene responsible for production of leptin, demonstrate hypoventilation in addition to marked obesity $\left(\mathrm{PaCO}_{2}\right.$ on average $1.5 \mathrm{kPa}$ higher than wild type mice during wakefulness). ${ }^{2}$ Furthermore, these animals have an impaired hypercapnic ventilatory response (HCVR) during both wakefulness and sleep. During REM sleep the HCVR is absent in ob/ob mice. This impairment of the HCVR in ob/ob mice relative to wild type mice cannot be attributed to the mechanical effects of obesity as it precedes the development of the latter. ${ }^{20}$ Furthermore, leptin replacement studies in ob/ob mice have shown improvements in baseline minute ventilation and HCVR during wakefulness and sleep under experimental conditions which prevented a concomitant weight change in the animal. ${ }^{21} 22$

\section{ROLE OF LEPTIN IN OSA}

The high prevalence of obstructive sleep apnoea (OSA) in obese humans ${ }^{23}$ and the established role of leptin as a respiratory stimulant and appetite suppressant in the mouse raised the possibility that sleep apnoea could be a leptin deficient state. Several groups have shown, however, that patients with OSA have even higher circulating leptin levels (approximately $50 \%$ ) than subjects without OSA matched for age and body mass index..24-26 This finding suggests that, independent of the known relationship between obesity and increased circulating leptin levels, OSA could represent a leptin resistant state. Two groups have shown that treatment of OSA with nasal continuous positive airway pressure (NCPAP) for 6 months is associated with a reduction in circulating leptin to a level similar to individuals without OSA. ${ }^{24}{ }^{26}$ The physiological explanation for the fall in circulating leptin levels in patients with OSA treated with NCPAP has not been fully elucidated, but some plausible explanations include a reduction in visceral fat accumulation, ${ }^{27}$ reduction in muscle sympathetic nerve activity, ${ }^{28}$ reduced level of stress, ${ }^{29}$ and a change in insulin responsiveness ${ }^{30}$ with NCPAP treatment. The fact that circulating leptin levels fall with NCPAP treatment of OSA, however, suggests that OSA may be a stimulant of leptin production rather than a consequence of the action of leptin.

\section{"A profound degree of leptin resistance may underpin the development of the obesity hypoventilation syndrome"}

The obesity hypoventilation syndrome (OHS) is characterised by obesity and hypercapnia while awake in the absence of an alternative neuromuscular, mechanical, or metabolic explanation for hypoventilation. Most patients with OHS suffer from OSA and in many (but not all) cases treatment of OSA with NCPAP restores daytime eucapnia. ${ }^{31}{ }^{32}$ In some patients OHS cannot be explained on the basis of OSA, ${ }^{33}$ and daytime hypercapnia appears to result from inadequate physiological compensation for the development of obesity alone. This condition remains an enigma. Why do certain obese individuals hypoventilate during wakefulness while others with similar or greater levels of obesity do not? Could leptin be the key to understanding this conundrum? 
The paper by Phipps and colleagues ${ }^{34}$ in this issue of Thorax contributes an interesting additional piece of information. The authors discovered that the mean serum leptin level was twice as high in a group of 12 hypercapnic obese humans as in a group of 44 eucapnic individuals with a similar percentage of body fat. Both groups had a mean apnoea-hypopnoea index in the severe OSA range but were not significantly different from each other. This finding raises the intriguing possibility that a profound degree of leptin resistance (more than that observed with eucapnic obesity or OSA alone) underpins the development of OHS. If this is the case, then leptin or analogues of leptin could have a role in the treatment of OHS. However, this preliminary finding by Phipps and colleagues will require further exploration to determine whether the marked increase in serum leptin levels found in patients with OHS truly signals a causative mechanism or whether it is simply an epiphenomenon of the condition. In particular, it would be interesting to know whether serum leptin levels are raised in patients with OHS but without significant OSA compared with patients with a similar level of simple obesity, whether leptin levels are increased in non-obese patients with hypoventilation, and whether the serum leptin level in patients with OHS reverts with treatment to the level observed in simple obesity, as might be expected if the increased serum leptin levels are a consequence rather than a causative factor in OHS. These questions and others with regard to the potential respiratory modulating role of leptin in humans, an exciting new research area, will probably find an answer within the next few years.

Thorax 2002;57: 1-2

\section{Author's affiliation}

M Fitzpatrick, Division of Respiratory and Critical Care Medicine, Queen's University, Kingston, Ontario K7L 3N6, Canada

Correspondence to: Dr M Fitzpatrick; mf19@post.qeensu.ca

\section{REFERENCES}

1 Zhang $Y$, Proenca $R$, Maffei $M$, et al. Positional cloning of the mouse obese gene and its human homologue. Nature 1994; 372:425-32.

2 Zhang F, Babinski MB, Beals JM, et al. Crystal structure of the obese protein leptin-E 100. Nature 1997;387:206-9.

3 Klein S, Coppack SW, Mohamed-Ali V, et al. Adipose tissue leptin production and plasma leptin kinetics in humans. Diabetes 1996;45:984-7.

4 Halaas JL, Gajiwala KS, Maffei M, et al. Weight-reducing effects of the plasma protein encoded by the obese gene. Science 1995;269:543-6.

5 Pelleymounter MA, Cullen M, Baker MB, et al. Effects of the obese gene product on weight regulation in ob/ob mice. Science 1995:269:540-3

6 Considine RV, Sinha MK, Heiman ML, et al. Serum immunoreactive-leptin concentrations in normal-weight and obese humans. N Engl J Med 1996:334:292-5.

7 Kolaczynski JW, Considine RV, Ohannesian $J$, et al. Responses of leptin to short-term fasting and refeeding in humans. Diabetes 1996;45: 1511-5.

8 Kolaczynski JW, Ohannesian JP, Considine $\mathrm{RV}$, et al. Response of leptin to short-term and prolonged overfeeding in humans. J Clin Endocrinol Metab 1996;81:4162-5.

9 Tartaglia L. The leptin receptor. J Biol Chem 1997;272:6093-6.

10 Flier JS, Maratos-Flier E. Obesity and the hypothalamus: novel peptides for new pathways. Cell 1998;92:437-40.

11 Mantzoros CS. Leptin and the hypothalamus: neuroendocrine control of food intake. Mol Psychiatry 1999:4:8-12.

12 Schwartz MW, Seeley RJ. Seminars in medicine of the Beth Israel Deaconess Medical Center. Neuroendocrine responses to starvation and weight loss. N Engl J Med 1997;336:1803-11.

13 Tritos N, Mantzoros CS. Leptin: its role in obesity and beyond. Diabetologia 1997; 40:1371-9.

14 Montague CT, Faroogi IS, Whitehead JP, et al. Congenital leptin deficiency is associated with severe early-onset obesity in humans. Nature 1997:387:903-8.

15 Caro JH, Sinha MK, Kolaczynski JW, et al. Leptin: the tale of an obesity gene. Diabetes 1996;45: 1455-62.

16 Willie JT, Chemelli RM, Sinton CM, et al. To eat or to sleep? Orexin in the regulation of feeding and wakefulness. Annu Rev Neurosci 2001;24:429-58.

17 Fried SK, Ricci MR, Russell CD, et al. Regulation of leptin production in humans. $J$ Nutr 2000;130:3127-31S.

18 Mantzoros CS. The role of leptin in human obesity and disease: a review of current evidence. Ann Intern Med 1999;130:671-80.

19 Simon C, Gronfier C, Schlienger JL, et al. Circadian and ultradian variations of leptin in normal man under continuous enteral nutrition: Relationship to sleep and body temperature. J Clin Endocrinol Metab 1998;83:1893-9.
20 Tankersley CG, Kleeberger S, Russ B, et al. Modified control of breathing in genetically obese (ob/ob) mice. J Appl Physiol 1996;81:716-23.

21 O'Donnell CP, Schaub CD, Haines AS, et al. Leptin prevents respiratory depression in obesity. Am J Respir Crit Care Med 1999;159: 1477-84.

22 Tankersley CG, O'Donnell C, Daood M. Leptin attenuates respiratory complications associated with the obese phenotype. J Appl Physiol 1998;85:2261-9.

23 Young T, Palta $M$, Dempsey J, et al. The occurrence of sleep-disordered breathing among middle-aged adults. N Engl J Med 1993;328: 1230-5

24 Vgontas AN, Papanicolaou DA, Bixler EO, et al. Sleep apnea and daytime sleepiness and fatigue: relation to visceral obesity, insulin resistance, and hypercytokinemia. J Clin Endocrinol Metab 2000;85:1 151-8.

25 Phillips BG, Kato M, Narkiewicz K, et al. Increases in leptin levels, sympethetic drive, and weight gain in obstructive sleep apnea. Am J Physiol Heart Circ Physiol 2000;279: H234-7.

26 Ip MSM, Lam KSL, Ho C, et al. Serum leptin and vascular risk factors in obstructive sleep apnea. Chest 2000;1 18:580-6.

27 Chin K, Shimizu K, Nakamura T, et al. Changes in intra-abdominal visceral fat and serum leptin levels in patients with obstructive sleep apnea syndrome following nasal continuous positive airway pressure therapy. Circulation 1999:100:706-12.

28 Snitker S, Pratley RE, Nicolson M, et al. Relationship between muscle sympathetic nerve activity and plasma leptin concentration. Obes Res 1997;5:338-40.

29 Heiman MI, Ahima LS, Craft B, et al. Leptin inhibition of the hypothalamic-pituitary-adrenal axis in response to stress. Endocrinology 1997: 138:3859-63.

30 Brooks B, Cistulli PA, Borkman M, et al. Obstructive sleep apnea in obese noninsulin-dependent diabetic patients: effect of continuous positive airway pressure treatment on insulin responsiveness. J Clin Endocrinol Metab 1994;79:1681-5

31 Sullivan CE, Berthon-Jones M, Issa F. Remission of severe obesity hypoventilation syndrome after short term treatment during sleep with continuous positive airway pressure. Am Rev Respir Dis 1983;128:177-81.

32 Berthon-Jones $\boldsymbol{M}$, Sullivan CE. Time course of change in ventilatory response to $\mathrm{CO}_{2}$ in long-term CPAP treatment for obstructive sleep apnea. Am Rev Respir Dis 1987;135: 144-7.

33 Jokic R, Zintel T, Gallagher CG, et al. Ventilatory chemoresponsiveness in relatives of patients with obesity hypoventilation syndrome and normal subjects. Thorax 2000;55:940-5.

34 Phipps PR, Starritt E, Caterson I, et al. Association of serum leptin with hypoventilation in human obesity. Thorax 2001;57:75-6. 


\section{Whose lung is it anyway?}

\section{T Treasure}

\section{Should the decision to operate be made by patients with NSCLC or their doctors?}

T he central point of the argument in the paper by Dowie and Wildman in this issue of Thorax ${ }^{1}$ is that it is the patient, not the doctors, who should decide whether to take the risk of an operation in the hope of curing lung cancer. I agree, and I know from working with a number of chest physicians on a regular basis that the patient's preference is genuinely central in decisions made about treatment. What is less certain is whether the choices being made are as explicit and as fully informed as would be necessary to implement decision analysis as espoused in this paper. ${ }^{2}$ My purpose is to ground the ideas in the context of current clinical practice and to see how near or far we are from patient determined decision making.

\section{MAKING THE DIAGNOSIS}

Firstly, the diagnosis must be knownincluding stage and cell type-and an estimate of prognosis made before the decision table can be entered. Dowie and Wildman's starting point is stage Ia nonsmall cell lung cancer. Clinicians will know that preoperative staging is never certain (if it were, we could claim a $100 \%$ surgical cure rate for NOMO disease), but with increasing use of FDG-PET (fluorodeoxyglucose positron emission tomography) in addition to CT scanning and mediastinoscopy as appropriate, we get as near to a diagnosis of stage Ia disease as is currently possible.

\section{INFORMING THE PATIENT}

We must also tell the patient. There are strategies for "breaking bad news" and it is never easy; it is we, the clinicians, who have to do it, but do it we must. ${ }^{3}$ In current practice not telling the patient can rarely be justified and we cannot have a decision analysis based on "gradual disclosure" $^{\prime 4}$ and other forms of well intentioned evasion. Now the scene is set to enter the decision making process. We have a diagnosis and an informed patient. The next step is to populate the decision tree with data to inform the choice.

\section{INSERTING DATA IN THE DECISION TREE}

Dowie and Wildman refer to $4 \%$ and $8 \%$ as relatively fixed cut off rates for surgical mortality for lobectomy and pneumonectomy, respectively. It is important to understood where these numbers come from.

Cardiothoracic surgeons have kept national registers of operations and survival figures dating back well over 30 years. ${ }^{5}$ These have been among the best in any specialty and any country. They have been collated annually and circulated to all members of the Society of Cardiothoracic Surgeons and used to reflect upon practice and an individual surgeon's performance. The data were provided voluntarily but have now been faulted for being made anonymous. When the Bristol balloon went up, the system was changed as a result of discussions between the GMC and the Society so that now all surgeons send in results for marker operations. All members doing thoracic surgery report 30 day mortality rates for lobectomy for lung cancer (without any adjustment for relative risk). Any surgeon whose results are above a threshold figure-and this is where the figures of $4 \%$ and $8 \%$ come from-can expect to be informed of the fact by the senior officers of the Society and for his or her health trust and medical director also to be informed. As I have pointed out elsewhere, ${ }^{6}$ this is an example of the way in which legislation intended to alter behaviour for the better may have another unintended consequence (the Rackman effect). In this instance it will make surgeons shy away from high risk cases to protect their annual summary statistic.

Surgeon specific data are available on 92 surgeons who performed a total of 1511 operations under the heading of lobectomy for cancer in 1999-2000. The median was 12 operations with an interquartile range of 5-27. Forty seven surgeons did 12 or fewer lobectomies a year (no more than a case a month). At this volume a single death (for whatever reason and no matter how high risk the patient) puts the surgeon above the arbitrary threshold $(1 / 12=8.3 \%)$ but with hugely wide confidence intervals (95\% CI 0.2 to 38.5$)$. This is an inescapable problem if we subset data to ensure we are comparing like with like, the simplistic (and in my view worn out) "apples and oranges" approach to statistical analysis. The numbers we end up with are too small to achieve any stability in the event rate. $^{7}$ I prefer the alternative approach of taking as large a proportion of the surgeon's practice as is feasible and intelligently applying a well informed and validated system of risk adjustment before making any comparisons or adjudication. ${ }^{8}$ However, it is an average risk over the surgeon's series of cases, not a level of acceptable risk for an individual patient, that was originally intended. ${ }^{9}$

\section{PATIENT-DOCTOR COMMUNICATION}

To return to our patient. She will know by now that she has cancer. She will perceive cancer, if untreated, as a death sentence (pace the slogan "cancer is a word not a sentence" ). ${ }^{4}$ She is likely to know that referral to a surgeon or the discussion of surgery with her physician means that she has been "lucky" enough to be one of the $10-20 \%$ where the cancer has not yet spread outside of the lung itself and surgical excision will (probably) cure it. What operative risk will she take? Dowie and Wildman are absolutely right. Faced with that situation a rational and well informed patient may willingly accept a risk of $10 \%, 20 \%$, or even $40 \%$.

I have had these discussions many times with patients and with colleagues. Surgery lends itself to this sort of debate more readily than many other treatments. Repeatedly in life and in the care of our patients we come to a point in the woods where the paths diverge and we must make a decision, but the surgical route is a one way street. Once the thoracotomy is performed, the risk is taken and any damage cannot be undone. Furthermore, it is not "the chance of dying on the table"1 (which is extraordinarily rare), but of dying slowly in the intensive care unit, of living on miserably short of breath, and/or eventually succumbing to cancer just the same. These are the downsides of the failure to deliver the hoped for uncomplicated cure and the difficulties that clinicians face in helping their patients towards the right choice for them. Even if the patient is prepared to take a $40 \%$ risk of perioperative death, can we possibly justify that as part of our clinical practice? There is an overall death rate which surgeons, anaesthetists, theatre staff, and ward nurses can cope with, but $40 \%$ would be carnage and expensive per life saved. I do not think that is what was envisaged.

Some clinicians will argue further that to hand over the decision to the patient is an abdication of our duty of care as doctors-it is a "cop out". For example, if I go to a professional for advice- $\mathrm{a}$ solicitor, an architect, a surveyor, a financial adviser, a plumber-I want their advice, not an overwhelming list of bewildering options. However, I think I 
am reasonably in agreement with Dowie and Wildman on this one. If my garage mechanic sells me a new gear box for my car with 110000 miles on the clock, only for it to come to a halt a few weeks later with the next problem, I may wonder if I was given an even handed presentation of my options. I also know from years of experience in discussing prophylactic replacement of the aortic root in Marfan's syndrome ${ }^{10}$ that, presented with the same set of probabilities, some opt to procrastinate (to come back for another echocardiogram next year) and others want to take the risk as soon as the surgical option is presented to them. ${ }^{10}{ }^{11}$ Both are rational and I respect them equally. However, even in that relatively clear example of decision making we have puzzled over how to weigh the options. Should the operative risk be set against the probability of coming back alive for the next year's root measurement, or should it be a computation of life time risks for the two strategies?

\section{FUTURE CHALLENGES}

In welcoming this work I have two challenges for Dowie and Wildman. The first is a general one. Lung cancer, with 40000 cases diagnosed each year, is common and rapidly fatal. Its care has fallen way behind that of the other common cancers. ${ }^{12}{ }^{13}$ Five year survival rates for lung cancer in the UK are among the lowest in Europe $^{14}$ and resection ratesthat is, the proportion, expressed as a percentage of cases, where an operation is performed to eradicate the cancerare of the order of $10 \%,{ }^{15-18}$ half or less than in Holland ${ }^{19}$ and the United States. ${ }^{20}$ Elderly patients in the UK are even less likely to have surgery for lung cancer. ${ }^{15}{ }^{18}$ Lung cancer care needs a rapid injection of resources. First in the queue for manpower expansion are oncologists and thoracic surgeons, but following on will be the need for pathologists, anaesthetists, and other members of cancer teams. The London School of Hygiene and Tropical Medicine has established for itself a pivotal role in health policy, evaluation of health services and, in general, the numerate end of healthcare thinking. A drive for lung cancer from its Public Health and Policy Department would be a fillip to those working against enormous odds with this terrible disease.

The second is a more personal one. Dowie and Wildman's work seeks to inform decision making in lung cancer but one senses that thus far it is a theoretical exercise, untested in the actual process of doctor-patient interaction. ${ }^{21} \mathrm{I}$ believe many of us have been using this approach for years, but we have relied on much less explicit rules and rather home spun approaches. Collaborative work with clinicians, combining theory with practice, is surely the way ahead. We have to make these decisions with patients all the time, albeit imperfectly. Let me publicly invite Professor Dowie and his colleagues to help us in exploring this approach in the care of our patients and to seek to validate and refine the process.

Thorax 2002;57:3-4

\section{Author's affiliation}

T Treasure, Department of Thoracic Surgery,

Guy's Hospital, London SEI 9RT, UK

Correspondence to: Professor T Treasure

\section{REFERENCES}

1 Dowie J, Wildman M. Choosing the surgical mortality threshold for high risk patients with stage la non-small cell lung cancer: insight from decison analysis. Thorax 2002;57:7-10.

2 Canter R. Patients and medical power. Shifting power in favour of the patient may not be so straightforward. BM 2001;323:414.

3 Jenkins V, Fallowfield L, Saul J. Information needs of patients with cancer: results from a large study in UK cancer centres. Br.J Cancer 2001;84:48-51.

4 Diamond JC. Because cowards get cancer too. London: Vermilion, 1998

5 English TAH, Bailey AR, Dark JF, et al. The UK Cardiac Surgical Register 1977-1982. BM 1984;289:1205-8.

6 Keogh BE, Kinsman R. National adult cardiac surgical database report. London: The Society of Cardiothoracic Surgeons of Great Britain and Ireland, 2001

7 Treasure T. Rational decision-making about paediatric cardiac surgery. Lancet 2000;355:948.

8 Treasure $\mathrm{T}$. Risks and results of surgery. $\mathrm{Br}$ Heart J 1995;74:1 1-2.

9 British Thoracic Society and Society of Cardiothoracic Surgeons of Great Britain and Ireland. Guidelines on the selection of patients with lung cancer for surgery. Thorax 2001;56:89-108.

10 Treasure T. Elective replacement of the aortic root in Marfan's syndrome. Br Heart J 1993;69:101-3.

11 Kravitz RL, Melnikow J. Engaging patients in medical decision making. The end is worthwhile, but the means need to be more practical. BM 2001;323:584-5.

12 Does lung cancer need a lapel ribbon? Lancet 2000;356:1205.

13 Yung RC, Orens JB. Radicalism in therapy of lung cancer. Lancet 2001;357:1306-7.

14 Berrino R, Capocaccia R, Esteve J, et al. Survival of cancer patients in Europe: the EUROCARE-2 study. IARC Scientific Publications No 151. Lyon, France: World Health Organisation, International Agency for Research on Cancer, European Commission, 1999.

15 Brown JS, Eraut D, Trask C, et al. Age and the treatment of lung cancer. Thorax 1996:51:564-8

16 Laroche C, Wells F, Coulden R, et al. Improving surgical resection rate in lung cancer. Thorax 1998;53:445-9.

17 Gregor A, Thomson CS, Brewster DH, et al. Management and survival of patients with lung cancer in Scotland diagnosed in 1995: results of a national population based study. Thorax 2001;56:212-7.

18 Northern and Yorkshire Cancer Registry and Information Services (NYCRIS) Cancer treatment policies and their effect on survival (lung) key sites study. NYCRIS, 1999

19 Damhuis RA, Schutte PR. Resection rates and postoperative mortality in 7899 patients with lung cancer. Eur Respir J 1996;9:7-10.

20 Fry WA Menck HR, Winchester DP. The National Cancer Data Base report on lung cancer. Cancer 1996;77:1947-55.

21 Elwyn G, Edwards A, Eccles M, et al. Decision analysis in patient care. Lancet 2001;358:571-4. 


\section{Lung volume reduction surgery}

\section{T P Toma, P Goldstraw, D M Geddes}

\section{LVRS works, but can we make it safer?}

$\mathrm{T}$ here are now five controlled trials showing that lung reduction for emphysema can alter lung function, increase walking distance, and improve quality of life. ${ }^{1-5}$ There are problems with each study in terms of design, duration, and small sample size but, taken together, they give a strong message that lung volume reduction surgery (LVRS) has a role in the management of chronic obstructive pulmonary disease (COPD). However, we need much more evidence before we can define exactly what this role is and when to recommend surgery. In particular, we need better ways of predicting benefit and risk. We also need to understand how LVRS works in order to develop better and safer ways of doing it. The large National Emphysema Treatment Trial (NETT) study ${ }^{6}$ which began 2 years ago and is expected to take 4 years to complete will provide some of the answers, and early results are helping to define a high risk group. In an unusual move the New England Journal of Medicine allowed the president of the American Thoracic Society to e-mail all members warning them in advance of the publication of a report from NETT. Patients in the trial who had a low forced expiratory volume in 1 second ( $<20 \%$ predicted) and either homogenous emphysema or a very low transfer factor ( $<20 \%$ predicted) were at high risk of death and were unlikely to benefit from surgery. ${ }^{7}$ Based on these results, patients with severe emphysema will no longer be randomised to LVRS.

This means that the most needy group of patients can no longer hope to gain from this operation. Furthermore, emphysema is more often diffuse and homogeneous than limited and patchy, so only a minority are suitable for the operation. What, then, are the prospects for the large number with severe diffuse disease? Fortunately, at the same time as discouraging news came from the NETT trial, early evidence of success using a bronchoscopic approach was published. Ingenito et al developed a sheep model of emphysema by exposing them to inhaled papain and then compared surgical volume reduction with a bronchoscopic technique in which a fibrin based glue was used to collapse, seal, and scar target regions of abnormal lung. The residual volume and total lung capacity were increased by the papain induced emphysema and then reduced towards baseline by both volume reduction techniques. This volume reduction was sustained at 2-3 months and the magnitude of the changes was similar for both the surgical and the bronchoscopic techniques. The bronchoscopic approach produced fewer complications overall than surgery, although some target zones developed sterile abscesses distal to the glue.

\section{"Vast sums of money are being spent on developing new drug treatments for COPD ... only a fraction may do more good just by altering lung mechanics"}

Several methods have been proposed to induce bronchial obstruction and distal collapse as a means of achieving volume reduction in emphysema, and two worldwide patents (WO0l/02042 and WO0l/ 13839) were published in January this year. These proposed techniques include obstructed stents, biopolymers, and tissue glue, all of which might be inserted at fibreoptic or combined fibreoptic and rigid bronchoscopy. Joel Cooper, who pioneered volume reduction surgery ${ }^{9}$ and remains a leader in the field, has suggested an alternative approach. This takes forward an older idea of bypassing the flow limiting segment of the emphysematous airway by making holes to connect the peripheral lung units to the major cartilaginous airways. These "spiracles" could allow deflation of emphysematous lung units and so achieve volume reduction. All these methods seek to exploit the pathophysiology of emphysema and its correction by volume reduction. Naturally, better understanding of the mechanisms of benefit following LVRS would inform these ideas.

No trials of bronchoscopic volume reduction have yet been done in humans and many questions remain. In particular, it is not known whether, in the context of advanced human emphysema, lobar or segmental occlusion would result in partial lung collapse and what would be its time course. It is possible that collateral air drift would keep the emphysematous lung aerated. Similarly, there are theoretical risks of infection, sterile necrosis, air leaks, and distortion of other lung units or vessels. Conversely, there may be major benefits of this approach to add to the likely improvement in safety. For example, it might be possible to assess the effects of temporary occlusion of the bronchus in patients with diffuse disease to determine who will get a worthwhile clinical benefit from volume reduction before doing a definitive procedure. Also, it may be possible to design techniques of bronchial occlusion that would allow the infusion of drugs distally to encourage scarring or to treat any infection.

This is an exciting area of research with real prospects of early benefit for the large number of patients whose lives are restricted by breathlessness. Vast sums of money are being spent on developing new drug treatments for COPD, a condition in which most patients present for medical treatment when the lung is largely destroyed. Only a fraction of these funds may do more good just by altering lung mechanics.

Thorax 2002;57:5

\section{Authors' affiliations}

T P Toma, P Goldstraw, D M Geddes Departments of Respiratory Medicine and Surgery, Royal Brompton Hospital, Sydney Street, London SW3 6NP, UK

Correspondence to: Professor D M Geddes; D.Geddes@rbh.nthames.nhs.uk

\section{REFERENCES}

1 Geddes D, Davies M, Koyama H, et al. Effect of lung volume reduction surgery in patients with severe emphysema. N Engl J Med 2000;343:239-45.

2 Criner GJ, Cordova FC, Furukawa S, et al. Prospective randomized trial comparing bilateral lung volume reduction surgery to pulmonary rehabilitation in severe chronic obstructive pulmonary disease. Am J Respir Crit Care Med 1999;160:2018-27.

3 Pompeo E, Marino M, Nofroni l, et al. Reduction pneumoplasty versus respiratory rehabilitation in severe emphysema: a randomized study. Pulmonary Emphysema Research Group. Ann Thorac Surg 2000;70:948-53.

4 Löfdahl C-G, Hillerdal G, Ström K, et al. Randomized controlled trial of volume reduction surgery: preliminary results up to 12 months. Am J Respir Crit Care Med 2000;161:A585

5 Goodnight-White S, Jones JW, Baaklini WA, et al. Lung volume reduction surgery (LVRS) in patients with severe emphysema: 1 year follow-up. Am J Respir Crit Care Med 2001; 163:A486.

6 National Emphysema Treatment Trial Research Group. Rationale and design of the National Emphysema Treatment Trial: a prospective randomized trial of lung volume reduction surgery. Chest 1999;116:1750-61

7 National Emphysema Treatment Trial Research Group. Patients at high risk of death after lung volume reduction surgery. N Engl J Med 2001;345: 1075-83

8 Ingenito EP, Reilly JJ, Mentzer SJ, et al Bronchoscopic volume reduction. A safe and effective alternative to surgical therapy for emphysema. Am J Respir Crit Care Med 2001;164:295-301.

9 Cooper JD, Patterson GA, Sundaresan RS, et al. Results of 150 consecutive bilateral lung volume reduction procedures in patients with severe emphysema. J Thorac Cardiovasc Surg 1996;112:1319-29. 


\section{NOTICE OF DUPLICATE PUBLICATION}

It has been brought to our attention that an article by Paul Corris entitled "A practical approach to the diagnosis of venothromboembolism" published in the CME General Internal Medicine section of Clinical Medicine 2001;1:274-81 includes substantial duplication of paragraphs published in a supplement to Thorax entitled "Suspected acute pulmonary embolism: a practical approach" (Thorax 1997;52(Suppl 4):SI-24)

Professor Corris adds the following comment: "I fully acknowledge that my article published in the CME General Internal Medicine Section of Clinical Medicine was based on a previous article published in a supplement to Thorax written by David Ellis, Noeleen Foley, Andrew Miller, and me. An initial sentence acknowledging the Thorax supplement as the basis of the article and the contribution of my co-authors should have been included, and this was a simple error of omission for which I apologise. I would, however, comment that the article published in Clinical Medicine was an invited review based on a talk given by me at a conference organised by the Royal College of Physicians and that my talk was based on the Thorax supplement. Furthermore, both articles comprised clinical reviews and it was my prior understanding that duplicate publication was defined as the deliberate attempt by an author to publish the same research data as a novel paper in more than one journal. It would now appear that the same rules apply to those writing reviews, and this is an important message for all who accept invitations to write such articles."

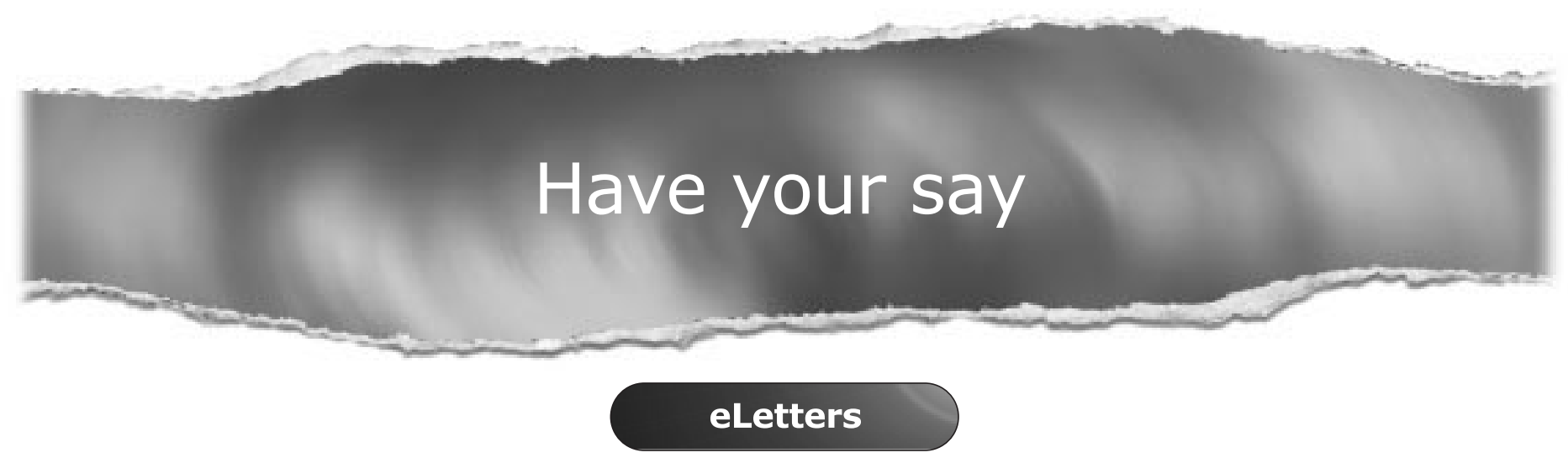

If you wish to comment on any article published in Thorax you can send an eLetter using the eletters link at the beginning of each article. Your response will be posted on Thorax online within a few days of receipt (subject to editorial screening).

\section{www.thoraxjnl.com}

